\title{
Roles of Autophagy and Autophagy-Related Proteins in Antifungal Immunity
}

\author{
Masashi Kanayama $^{1}$ and Mari L. Shinohara ${ }^{1,2 *}$ \\ ${ }^{1}$ Department of Immunology, Duke University School of Medicine, Durham, NC, USA, ${ }^{2}$ Department of Molecular Genetics \\ and Microbiology, Duke University School of Medicine, Durham, NC, USA
}

Autophagy was initially characterized as a process to digest cellular components, including damaged cell organelles or unused proteins. However, later studies showed that autophagy plays an important role to protect hosts from microbial infections. Accumulating evidences showed the contribution of autophagy itself and autophagyrelated proteins (ATGs) in the clearance of bacteria, virus, and parasites. A number of studies also revealed the molecular mechanisms by which autophagy is initiated and developed. Furthermore, it is now understood that some ATGs are shared between

OPEN ACCESS

Edited by:

Diana Bahia,

Universidade Federal de Minas

Gerais, Brazil

Reviewed by:

Eleonora Garcia Vescovi, Instituto de Biología Moleculary Celular de Rosario, Argentina

Georgios Chamilos,

University of Crete, Greece

${ }^{*}$ Correspondence:

Mari L. Shinohara

mari.shinohara@duke.edu

Specialty section:

This article was submitted to Microbial Immunology, a section of the journal Frontiers in Immunology

Received: 14 December 2015

Accepted: 31 January 2016 Published: 18 February 2016

Citation:

Kanayama $M$ and Shinohara ML (2016) Roles of Autophagy and Autophagy-Related Proteins in

Antifungal Immunity.

Front. Immunol. 7:47.

doi: 10.3389/fimmu.2016.00047 two distinct processes; autophagy and LC3-associated phagocytosis (LAP). Thus, our understanding on autophagy has been greatly enhanced in the last decade. By contrast, roles of autophagy and ATGs in fungal infections are still elusive relative to those in bacterial and viral infections. Based on limited numbers of reports, ATG-mediated host responses appear to significantly vary depending on invading fungal species. In this review, we discuss how autophagy and ATGs are involved in antifungal immune responses based on recent discoveries.

Keywords: autophagy, LC3-associated phagocytosis, fungal infection, phagocytosis, macrophages, Candida, Cryptococcus, Aspergillus

\section{HOST IMMUNITY AGAINST FUNGI}

Pathogenic fungi, such as Cryptococcus, Candida, Aspergillus, and Pneumocystis, are considered to be four major genera of human fungal pathogens (1). A major host risk factor for development of these fungal infections (mycosis) is immunological incompetence, as they are more commonly invasive in patients with immunodeficient disorders and those who receive immunosuppressive treatments $(2,3)$.

The innate immune system plays a critical role in host protection against fungi. Specific defects in innate immunity, such as neutropenia or functional deficiency of NADPH oxidase, allow hosts to develop invasive aspergillosis, candidiasis, and other mycosis $(3,4)$. For hosts to initiate antifungal immune responses, fungi have to be detected by pattern recognition receptors (PRRs). Neutrophils and inflammatory macrophages are the first inflammatory cells recruited to the site of infection and the major killers of fungi during an early stage of infection. Dendritic cells (DCs) serve an important role as professional antigen-presenting cells (APCs) to connect innate and adaptive immunity by presenting fungal antigens to prime naïve $\mathrm{T}$ cells. As seen in all the microbial infections, coordinating innate immunity is the first step to protect hosts from fungal pathogens. 
Defects in the adaptive immune systems are also well-known risk factors in fungal infections. Once primed by DCs, T cells activate and produce inflammatory cytokines, which further recruit innate immune cells to infected sites and facilitate phagocytosis $(5,6)$. B cells are also involved in fungal clearance $(7,8)$ by producing antibodies to opsonize fungal spores, i.e., antibodies binds spores and facilitate phagocytosis through stimulating FC Receptor on phagocytes $(9,10)$.

In this review, we discuss on autophagy and autophagy-related processes in host cells during fungal infections as a part of the immune responses described above.

\section{AUTOPHAGY}

Autophagy is a highly conserved cellular process in eukaryotes to maintain cellular homeostasis by supporting cell survival and regulating inflammation. Autophagy degrades unnecessary or dysfunctional intracellular components, such as abnormal proteins, old organelles, and pathogens, and has been widely studied in various immune cells, including T cell, B cell, macrophages, DCs, and neutrophils. Autophagy eliminates mitochondoria (mitophagy), lipid droplets (lipophagy), ribosomes (ribophagy), protein aggregates (aggrephagy), and intracellular microbes (xenophagy) $(11,12)$. Multiple roles for autophagy in host defense responses against microbial infections and inflammation have been reported. During a process of autophagy, a spherical double-membrane structure, termed autophagosome, is formed within a cell. A number of autophagy-related proteins (ATGs), together with other proteins, are involved in the process to form autophagosomes; starting from the formation of the autophagy initiation complex to elongating autophagosome membranes. After elongation, the membrane closes and autophagosome formation is completed. [Detailed molecular information on these steps can be found in excellent review articles $(13,14)]$.

It has been reported that ATGs are associated with human autoimmune disorders, cancer, and various infectious diseases (15). Single-nucleotide polymorphisms (SNPs) in ATG16L and Immunity-related GTPase family $M$ member (IRGM) genes are known to increase the risk of Crohn's disease $(16,17)$. A SNP of IRGM is also associated with susceptibility against Mycobacterium tuberculosis infection $(18,19)$, and SNPs in ATG5 are associated with risk of systemic lupus erythematosus (20). UV radiation resistance-associated gene (UVRAG) encoding a promoter of the autophagy pathway, is monoallelically mutated at a high frequency in human colon cancer (21). Recent study demonstrated that Atg5 in neutrophils protects mice from M. tuberculosis infection in autophagy-independent manner (22). Thus, autophagy and autophagy-related genes are suggested to be involved in pathogenesis of wide variety of human diseases.

Recent mechanistic studies have shown that autophagy plays an immunomodulatory role in both innate and adaptive immune responses by selectively targeting signal molecules. For example, autophagy inhibits inflammasome activation in macrophages by degrading inflammasome assemblies as well as reactive oxygen species (ROS)-producing mitochondria, which trigger activation of the NLRP3 inflammasome $(23,24)$. Autophagy is also known to be required for neutrophil extracellular trap formation (NETosis) (25-27) and immunological training induced by BCG or $\beta$-glucan in monocytes (28). In T cells, autophagy suppresses T cell receptormediated signaling by degrading BCL10, a downstream molecule of the T cell receptor (29). Autophagy also enhances memory B cell responses $(30,31)$. Collectively, these findings implicate autophagy in preventing excessive inflammation and protecting the host from collateral damage.

\section{LAP AND AUTOPHAGY}

LAP shares some common mechanisms and functions to autophagy; and it has been often difficult to separate LAP and autophagy. For example, LC3 staining cannot differentiate LAP from autophagy, because LC3-associated membranes are formed during both processes. LAP formation requires autophagic proteins, such as ATG5, ATG7, and LC3; therefore, mice or cells lacking one of these proteins cannot undergo both autophagy and LAP (32). Initiation of autophagy and LAP also require ROS and phosphatidylinositol 3-phosphate synthesis (33, 34); although ROS-independent LAP formation was reported in epithelial cells (35), suggesting cell type-specific signaling requirements to induce autophagy or LAP. It is possible that autophagy in nonhematopoietic cells is involved in induction of host antifungal responses. Similarly to autophagy's contribution to microbial clearance by digesting intracellular pathogens, LAP also plays a role in pathogen clearance $(36,37)$. Despite the similarities, LAP is intrinsically distinct from autophagy in forming the LAPosome with a single membrane structure $(32,38)$, the requirement of Rubicon and NOX2 (33), and not requiring the autophagy preinitiation complex comprised of ULK1/2, FIP200, and ATG13 $(33,39,40)$.

A very recent article demonstrated that LAP is differentiated from autophagy using Rubicon-deficient mice (autophagy is intact in the mice) (33). Here, we would like to note that previously published studies using Atg5- or Atg7-deficient mice or cells might reflect impacts of impaired LAP as well as autophagy, though most of them have been published as "autophagy" studies. Therefore, it would be prudent to consider the possible involvement of LAP in previous studies, depending on an experimental condition. In this review, we use "LC3-associated cargoes" for autophagosomes and LAPosomes if responses in referred articles have not identified as autophagy or LAP.

\section{ROLES OF AUTOPHAGY-RELATED PROTEINS IN FUNGAL INFECTIONS}

The role of autophagy in antifungal immunity was strongly suggested both in mammals and plants (41). Here, we focus on autophagy in mammalian cells. Autophagy can be induced directly by signaling from fungal-sensing PRRs, and also indirectly by pro-inflammatory cytokines, including TNF- $\alpha$, IL-6, IL-1, and IFN- $\gamma$ (42) during fungal infections. In contrast, spores of Aspergillus fumigatus induce LAP based on the study using Rubicon-deficient mice (33). LAP is also induced by zymosan, a cell-wall component from Saccharomyces cerevisiae (33). Therefore, it is possible that other fungi induce LAP. In 
the following subsections and Table 1, we focus on three major fungal pathogens: Candida albicans, Cryptococcus neoformans, and A. fumigatus to discuss impacts of ATGs on host antifungal responses and pathogenesis of fungal infections.

\section{Candida albicans}

Several studies have described roles of "autophagy" (or possibly LAP) during Candida infection. Candida spores, both live and heat-killed, are potent inducers of LC3 puncta formation and conversion of LC3-I to LC3-II (43-45). However, it appears that live Candida spores are not good at recruiting LC3 around internalized spores $(43,45,46)$. These results suggest that live Candida can induce autophagy (and/or LAP), but direct clearance of Candida spores within LC3-associated cargoes is not likely to occur. A study by Vyas and colleagues showed that heat-killed $C$. albicans (HKCA) recruited clear LC3-associated cargoes around

\section{TABLE 1 | Impacts of autophagy and LAP on antifungal immunity.}

\begin{tabular}{|c|c|c|c|}
\hline & Approaches & Findings & Reference \\
\hline \multirow[t]{2}{*}{ A. fumigatus } & 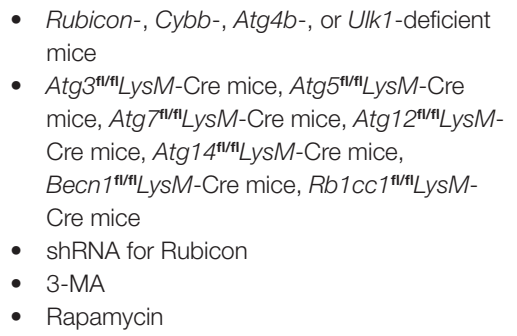 & $\begin{array}{l}\text { - A. fumigatus phagocytosed by macrophages induces LAP formation } \\
\text { - LAP, but not canonical autophagy, is required for clearance of } A \text {. fumigatus } \\
\text { in vitro and in vivo. } \\
\text { - Lack of LAP enhances fungi-induced pulmonary inflammation and granulomas } \\
\text { - SNP in Atg16L does not affect LAP formation }\end{array}$ & (33) \\
\hline & $\begin{array}{l}\text { - 3-MA } \\
\text { - Chloroquine }\end{array}$ & $\begin{array}{l}\text { - Autophagy suppresses inflammasome-mediated inflammation during } \\
\text { A. fumigatus infection } \\
\text { - IL-1R blockade restores autophagy and suppresses fungal growth in CGD mice. }\end{array}$ & $(58)$ \\
\hline \multirow[t]{2}{*}{ C. neoformans } & $\begin{array}{l}\text { - } \text { RNAi screening } \\
\text { MiRNA for Atg2a, Atg5, Atg9, Atg12, and } \\
\text { - } 3 \text { 3-MA }\end{array}$ & $\begin{array}{l}\text { - Knockdown of Atg5, Atg9a, and Atg12 decreases phagocytosis of } \\
\text { C. neoformans by macrophages } \\
\text { - Knockdown of Atg2a, Atg5, Atg9a, Atg12, and LC3 decreases fungal replication } \\
\text { and escape of C. neoformans } \\
\text { - Autophagy inhibition by 3-MA reduces phagocytosis, fungal replication, and } \\
\text { escape of C. neoformans }\end{array}$ & (54) \\
\hline & $\begin{array}{l}\text { - } \quad \text { shRNA for Atg5 } \\
\text { - } \quad \text { Atg5 } 5^{\mathrm{fl} / \mathrm{f} / L y s M-C r e ~ m i c e}\end{array}$ & $\begin{array}{l}\text { - Phagocytosed C. neoformans are surrounded by LAP in macrophages } \\
\text { - Atg5-knock down by shRNA does not affect phagocytosis } \\
\text { - Atg5-knock down by shRNA or Atg5-knock-out decreases fungicidal activity in } \\
\text { macrophages }\end{array}$ & $(50)$ \\
\hline \multirow[t]{5}{*}{ C. albicans } & $\begin{array}{l}\text { - } \quad \text { shRNA for Atg5 } \\
\text { - } \quad \text { Atg5 } 5^{\mathrm{fl} / \mathrm{fI} L y s M-C r e ~ m i c e}\end{array}$ & $\begin{array}{l}\text { - Phagocytosed C. albicans are surrounded by LC3 in macrophages } \\
\text { - Atg5-knockdown decreases phagocytosis and fungicidal activity of } \\
\text { macrophages in vitro } \\
\text { - Lack of ATG5 in myeloid cells enhances susceptibility of mice against systemic } \\
\text { C. albicans infection }\end{array}$ & $(50)$ \\
\hline & $\begin{array}{l}\text { - } \quad \text { Atg } 7^{\mathrm{fl} / \mathrm{fl} L y s M-C r e ~ m i c e} \\
\text { - } 3-\mathrm{MA} \\
\text { - } \text { Cohort study of candidemia patients }\end{array}$ & $\begin{array}{l}\text { - Lack of ATG7 in myeloid cells does not impact on susceptibility of mice against } \\
\text { systemic C. albicans infection } \\
\text { - Autophagy inhibition by 3-MA does not affect phagocytosis and fungicidal } \\
\text { activity against C. albicans in human monocytes } \\
\text { - SNP in autophagy-related genes does not associate with incidence of } \\
\text { candidemia }\end{array}$ & $(44)$ \\
\hline & $\begin{array}{l}\text { - } \quad \text { Atg } 7^{\mathrm{fl} / \mathrm{fl} L y s M-C r e ~ m i c e} \\
\text { - } 3-\mathrm{MA} \\
\text { - Rapamycin }\end{array}$ & $\begin{array}{l}\text { - C. albicans induces autophagy in macrophages enhances susceptibility against } \\
\text { systemic C. albicans infection } \\
\text { - Phagocytosed C. albicans are not surrounded by LC3 } \\
\text { - Autophagy does not affect phagocytosis and fungicidal activity of macrophages } \\
\text { and neutrophils } \\
\text { - Autophagic sequestration of A20 enhances NFKB-mediated chemokine } \\
\text { production in tissue-resident macrophages and increases neutrophil recruitment } \\
\text { to infected site } \\
\text { - Lack of autophagy in myeloid cells }\end{array}$ & $(43)$ \\
\hline & - In vivo imaging using zebra fish & - Very few LC3+ phagosome contain C. albicans in vivo & $(46)$ \\
\hline & - LC3-deficient BMMs & $\begin{array}{l}\text { - Dectin-1-induced signaling triggers LAP formation in macrophages } \\
\text { - HK C. albicans induces LAP in macrophages } \\
\text { - Live C. albicans induces modest level of LAP in macrophages } \\
\text { - LC3-deficiency decreases fungicidal activity of macrophages against } \\
\text { C. albicans }\end{array}$ & $(45)$ \\
\hline
\end{tabular}


spores by in vitro observation using the RAW264.7 mouse macrophage cell line. By contrast, when live $C$. albicans was internalized, LC3-associated cargoes around spores were not very clear (45). The result is consistent with an in vivo study using zebra fish, in which live C. albicans rarely recruited significant levels of LC3 (46). We also could not detect LC3 signal surrounding live $C$. albicans in both primary macrophages and in a macrophage cell line (43). This finding was unexpected, because we speculated that Candida spores were engulfed in LC3-positve cargoes and directly killed by xenophagy or LAP. The expectation came from previous reports showing successful recruitment of LC3 to zymosan particles (33) and around $\beta$-glucan-coated polystyrene beads (45, 47). However, it is possible that live Candida spores do not expose enough $\beta$-glucan on their cell surface, while HKCA spores do (45, 48,49 ). Collectively, these studies suggested that direct killing of Candida spores within LC3-associated cargoes is not very likely.

Despite the unexpectedly poor engulfment of live Candida in LC3-associated cargoes, studies have shown that autophagy (or LAP) protects hosts from Candida infections. Lack of ATG5 or ATG7 in myeloid cells decreased resistance against systemic $C$. albicans infection $(43,50)$. The protective role of autophagy (or LAP) in Candida infection is partly attributed to enhanced fungicidal activity in host myeloid cells, such as expression of ROS and efficiency of phagocytosis (50). Here, we should mention that host protection by autophagy or LAP during Candida infection might not be always apparent. Smeekens et al. reported no difference in survival between wild-type and Atg7 conditional knock-out myeloid cells (Atg7 CKO), as well as no difference in phagocytosis and killing of Candida (44). Although we found that Atg7 CKO mice are more sensitive to systemic Candida infection, we also found no difference in phagocytosis and killing of Candida with or without ATG7 (43). Reasons for the discrepancy may be experimental conditions and differential strain usage of C. albicans. For example, Smeekens et al. used a different strain of C. albicans (MYA-3573) from others (SC-5314, 18804) $(43,45,50)$. We used strain 18804 and found that ATG7 in myeloid cells plays a protective role in hosts without enhancing phagocytosis and killing of Candida (43). Same host responses cannot be expected when Candida strains are different. For example, published articles suggested distinct dectin-1 detection towards two different Candida strains, SC-5314 and 18804 (51, 52). Taken together, multiple studies suggested the involvement of ATG5 and ATG7 in enhancing resistance to Candida infection.

As shown in human studies, despite moderate influences on pro-inflammatory cytokine production, autophagy genes ATG16L1 and IRGM have a minor impact on the susceptibility to both mucosal and systemic Candida infections (53). Other genes were investigated, such as ATG10, ATG16L2, ATG2A, ATG2B, ATG5, and $A T G 9 B$, but a clear correlation between SNPs of the genes and susceptibility to candidemia was not found (44). It was reported that an ATG16L human SNP mutant protein (T316A) expressed in mice decreases starvation-induced autophagy to $50 \%$ with no influence on zymosan-induced LAP (33). Nevertheless, impacts of these SNPs on autophagy and LAP in humans are still elusive. Therefore, further studies are needed to understand the consequence of autophagy on host immunity against Candida in humans.

\section{Cryptococcus neoformans}

Cryptococcusneoformans is an opportunistic fungus. Cryptococcal yeasts are encapsulated in polysaccharides and, thus, can evade immune detection by hosts. Interestingly, host autophagy supports intracellular survival and dissemination of C. neoformans (54). The report demonstrated that ATGs (ATG5, ATG9a, and ATG12) are engaged, but not required, in phagocytosing C. neoformans by RAW264.7 macrophages, and the proteins are recruited to the vicinity of vacuoles containing $C$. neoformans (54). At a later time point (15 h after infection), ATG2a, ATG5, ATG9a, ATG12, and LC3 enhance intracellular replication and escape of C. neoformans from vacuoles in macrophages (54). Indeed, pharmacological inhibition of autophagy by 3-MA reduced levels of Cryptococcus infection (54). Another article reported LC3 recruitment to internalized cryptococcal spores; and mouse survival from Cryptococcus infection was not altered by Atg5 CKO in myeloid cells (50). Nevertheless, the CKO mice exhibited reduced lung fungal burdens and protein expression of MIP-1 $\alpha$ (CCL3), IP-10 (CXCL10), as well as Type- 2 cytokines IL-4 and IL-13 (50). Expression of IFN- $\gamma$ and IL-17 did not appear to be altered (50). Therefore, further studies are awaited to better understand the impact and roles of autophagy (and LAP) in Cryptococcus infection.

\section{Aspergillus fumigatus}

LC3-II recruitment in A. fumigatus phagosomes was reported (55). A recent study using Rubicon-deficient mice clarified that LC3 recruitment and clearance of $A$. fumigatus are mediated by LAP, but not by autophagy (33). LAP protects mice from pulmonary aspergillosis by suppressing expression of pro-inflammatory cytokine genes and granuloma formation in the lung (33). LAP also stabilizes the NOX2 NADPH oxidase complex to produce ROS. Macrophages deficient for NOX2 failed to translocate LC3 to Aspergillus-containing phagosomes, as well as macrophages deficient for Beclin1, Rubicon, and ATG7 failed to do so (33). It was reported that patients with chronic granulomatous disease (CGD), caused by genetic defects in the NADPH oxidase, do not recruit LC3 around the Aspergillus-containing phagosomes (55). CGD patients indeed show an increased susceptibility to aspergillosis $(56,57)$. In addition, corticosteroid blocks recruitment of ATG (55), and its treatment is considered to be a risk factor for invasive aspergillosis (57). Another report demonstrated that IL-1R blockade protects hosts from invasive aspergillosis by increasing LC3 recruitment to Aspergillus-containing phagosomes and inhibiting fungal growth (58). In summary, LC3-associated cargoes appear to play a critical role in clearance of Aspergillus by host cells.

\section{IMMUNOMODULATION BY AUTOPHAGY DURING FUNGAL INFECTION}

\section{Regulation of Inflammasome-Mediated Immune Responses}

Recent studies showed that autophagy controls immune responses during fungal infections. Autophagosomes are known to sequester 
assembled NLRP3 inflammasome complexes $(23,24)$, which are crucial for host protection against $C$. albicans and A. fumigatus infections (59-61). Another study showed that pharmacological inhibition of autophagy by 3-MA or chloroquine enhances inflammasome activation and inflammation in mice during $A$. fumigatus infection (58). Increased inflammasome activity was reported in monocytes and macrophages from CGD patients (58, 62-64). Therefore, autophagy (or LAP) may protect hosts from collateral damage by inflammation through downregulating NLRP3 inflammasome, which is activated by fungal infections.

\section{NFкB-Mediated Immune Responses}

We have discussed autophagy-mediated suppression in immune responses $(23,29,65)$. Yet, autophagy can enhance antifungal immune responses in early stages of C. albicans infection by using mice conditionally lacking Atg7 in myeloid cells (Atg7 CKO) (43) (Table 1; Figure 1). The Atg7 CKO mice showed increased fungal burdens in infected sites as a result of reduced neutrophil recruitment. This was due to reduced production of neutrophilchemoattractants (CXCL1 and CXCL2) by tissue-resident macrophages at the site of infection in the absence of Atg7 (43) (Figure 1). Unstimulated tissue-resident macrophages express high levels of A20, an NFKB inhibitor (66-69). After detection of $C$. albicans, autophagy in tissue-resident macrophages sequesters A20 and frees NFkB activation from A20-mediated inhibition. Autophagy-adaptor protein p62 was demonstrated

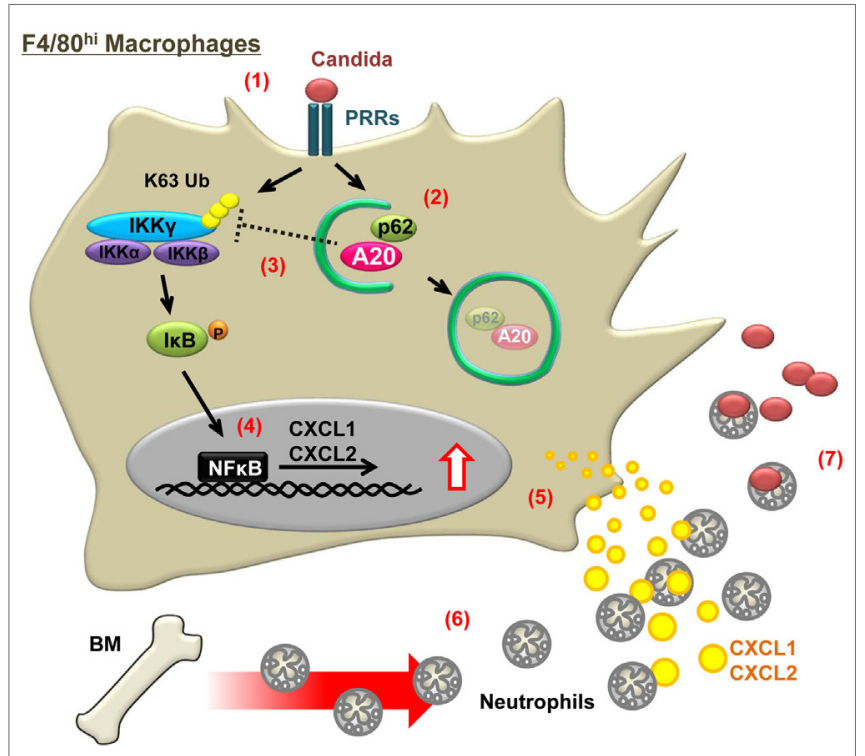

FIGURE 1 | Schematic illustration of a mechanism in which autophagy enhances antifungal immune responses by sequestering A20. Numbers in the figure indicate steps from fungal detection to killing by hosts and correspond to the following events: (1) detection of $C$. albicans by PRRs, such as dectin-1 and TLR2, expressed on F4/80 ${ }^{\text {hi }}$ tissue-resident macrophages; (2) autophagy induction and sequestration of A20 in autophagosomes, and A20 delivery to autophagosomes by p62; (3) IKK $\gamma$ ubiquitination by sequestering A20; (4) enhancement of NFKB activity; (5) increased chemokine production; (6) recruitment of neutrophils to infected sites (i.e., where the responding tissue-resident macrophages are located); and (7) Killing of fungi by neutrophils. to interact with A20 to carry A20 into LC3-associated cargos (43) (Figure 1). Indeed, the lack of ATG7 or p62 increases the levels of A20, causing reduction in NFKB activity and chemokine production by tissue-resident macrophages (43) (Figure 1). In summary, autophagy appears to function in balancing between inducing antifungal immunity and controlling excessive inflammation.

\section{IMPACTS OF AUTOPHAGY ON ADAPTIVE IMMUNITY}

Limited amount of autophagy information is available on adaptive immune responses against fungal pathogens, but the involvement of autophagy in shaping adaptive immunity to protect hosts against fungal infections has been suggested. Autophagy enhances survival and functions of T cells (70-72) and B cells $(73,74)$ in various pathological conditions. Autophagic machinery including ATG5 plays an important role in processing and presenting extracellular microbial antigens in dendritic cells (75). Importantly, LC3-associated cargoes are involved in presenting fungal antigen from S. cerevisiae (47). Thus, autophagy appears to control antifungal adaptive immune responses via antigen presentation by DCs and other APCs. It is still not clear whether autophagy in T cells directly controls antifungal immunity.

\section{CONCLUSION}

Autophagy was initially described as a self-catabolic process, but it is now known to play a critical role in clearance of bacterial, viral, and parasitic pathogens. Although the role of autophagy and ATGs in host defense against fungi had not been made clear, recent studies demonstrated the involvement of autophagy and ATGs in modulating antifungal immunity. LC3-associated cargoes may include fungal spores; but the inclusion cannot be always seen, e.g., when live Candida is engulfed. Autophagy and LAP generally protect hosts from majority of fungal infections by inducing immune responses or by controlling excessive inflammation. There are, however, some exceptions that ATGs promote fungal infections. The outcomes of autophagy/LAP in shaping host immune responses appear to greatly vary depending on species of fungi. Interestingly, previous findings suggested that activation of autophagy/LAP by immunosuppressants, such as rapamycin or anakinra (IL-1R antagonist), may result in inducing host resistance against fungal infections. It might be possible that autophagy-related pathways are targeted for new antifungal therapeutics.

\section{AUTHOR CONTRIBUTIONS}

MK and MLS wrote the manuscript.

\section{ACKNOWLEDGMENTS}

The authors wish to thank support from NIH (R01-AI088100 and R21-105584) to MLS. We also thank past and present laboratory members, particularly Will Barclay and Gregory Swan for their editorial help to prepare the manuscript. 


\section{REFERENCES}

1. Brown GD, Denning DW, Gow NA, Levitz SM, Netea MG, White TC. Hidden killers: human fungal infections. Sci Transl Med (2012) 4:165rv13. doi:10.1126/scitranslmed.3004404

2. Shimodaira K, Okubo Y, Nakayama H, Wakayama M, Shinozaki M, Ishiwatari $\mathrm{T}$, et al. Trends in the prevalence of invasive fungal infections from an analysis of annual records of autopsy cases of Toho University. Mycoses (2012) 55:435-43. doi:10.1111/j.1439-0507.2012.02169.x

3. Cornely OA. Aspergillus to Zygomycetes: causes, risk factors, prevention, and treatment of invasive fungal infections. Infection (2008) 36:296-313. doi:10.1007/s15010-008-7357-z

4. Bassiri-Jahromi S, Doostkam A. Fungal infection and increased mortality in patients with chronic granulomatous disease. J Mycol Med (2012) 22:52-7. doi:10.1016/j.mycmed.2011.12.079

5. Marodi L, Schreiber S, Anderson DC, MacDermott RP, Korchak HM, Johnston RB Jr. Enhancement of macrophage candidacidal activity by interferon-gamma. Increased phagocytosis, killing, and calcium signal mediated by a decreased number of mannose receptors. J Clin Invest (1993) 91:2596-601. doi:10.1172/JCI116498

6. Conti HR, Shen F, Nayyar N, Stocum E, Sun JN, Lindemann MJ, et al. Th17 cells and IL-17 receptor signaling are essential for mucosal host defense against oral candidiasis. J Exp Med (2009) 206:299-311. doi:10.1084/jem.20081463

7. Opata MM, Hollifield ML, Lund FE, Randall TD, Dunn R, Garvy BA, et al. B lymphocytes are required during the early priming of CD4+ T cells for clearance of pneumocystis infection in mice. J Immunol (2015) 195:611-20. doi:10.4049/jimmunol.1500112

8. Rohatgi S, Pirofski LA. Molecular characterization of the early B cell response to pulmonary Cryptococcus neoformans infection. J Immunol (2012) 189:5820-30. doi:10.4049/jimmunol.1201514

9. Subramaniam KS, Datta K, Quintero E, Manix C, Marks MS, Pirofski LA. The absence of serum IgM enhances the susceptibility of mice to pulmonary challenge with Cryptococcus neoformans. J Immunol (2010) 184:5755-67. doi:10.4049/jimmunol.0901638

10. Yuan R, Clynes R, Oh J, Ravetch JV, Scharff MD. Antibody-mediated modulation of Cryptococcus neoformans infection is dependent on distinct Fc receptor functions and IgG subclasses. J Exp Med (1998) 187:641-8. doi:10.1084/ jem.187.4.641

11. Nakahira K, Choi AM. Autophagy: a potential therapeutic target in lung diseases. Am J Physiol Lung Cell Mol Physiol (2013) 305:L93-107. doi:10.1152/ ajplung.00072.2013

12. Cuervo AM. Chaperone-mediated autophagy: Dice's 'wild' idea about lysosomal selectivity. Nat Rev Mol Cell Biol (2011) 12:535-41. doi:10.1038/ nrm 3150

13. Marino G, Niso-Santano M, Baehrecke EH, Kroemer G. Self-consumption: the interplay of autophagy and apoptosis. Nat Rev Mol Cell Biol (2014) 15:81-94. doi:10.1038/nrm3735

14. Mizushima N, Komatsu M. Autophagy: renovation of cells and tissues. Cell (2011) 147:728-41. doi:10.1016/j.cell.2011.10.026

15. Choi AM, Ryter SW, Levine B. Autophagy in human health and disease. NEngl J Med (2013) 368:651-62. doi:10.1056/NEJMra1205406

16. Salem M, Ammitzboell M, Nys K, Seidelin JB, Nielsen OH. ATG16L1: a multifunctional susceptibility factor in Crohn disease. Autophagy (2015) 11:585-94. doi:10.1080/15548627.2015.1017187

17. Parkes M, Barrett JC, Prescott NJ, Tremelling M, Anderson CA, Fisher SA, et al. Sequence variants in the autophagy gene IRGM and multiple other replicating loci contribute to Crohn's disease susceptibility. Nat Genet (2007) 39:830-2. doi:10.1038/ng2061

18. Che N, Li S, Gao T, Zhang Z, Han Y, Zhang X, et al. Identification of a novel IRGM promoter single nucleotide polymorphism associated with tuberculosis. Clin Chim Acta (2010) 411:1645-9. doi:10.1016/j.cca.2010.06.009

19. Bahari G, Hashemi M, Taheri M, Naderi M, Eskandari-Nasab E, Atabaki M. Association of IRGM polymorphisms and susceptibility to pulmonary tuberculosis in Zahedan, Southeast Iran. ScientificWorldJournal (2012) 2012:950801. doi:10.1100/2012/950801

20. Pierdominici M, Vomero M, Barbati C, Colasanti T, Maselli A, Vacirca D, et al. Role of autophagy in immunity and autoimmunity, with a special focus on systemic lupus erythematosus. FASEB J (2012) 26:1400-12. doi:10.1096/ fj.11-194175
21. Liang C, Feng P, Ku B, Dotan I, Canaani D, Oh BH, et al. Autophagic and tumour suppressor activity of a novel Beclin1-binding protein UVRAG. Nat Cell Biol (2006) 8:688-99. doi:10.1038/ncb1426

22. Kimmey JM, Huynh JP, Weiss LA, Park S, Kambal A, Debnath J, et al. Unique role for ATG5 in neutrophil-mediated immunopathology during M. tuberculosis infection. Nature (2015) 528:565-9. doi:10.1038/nature16451

23. Shi CS, Shenderov K, Huang NN, Kabat J, Abu-Asab M, Fitzgerald KA, et al. Activation of autophagy by inflammatory signals limits IL-1beta production by targeting ubiquitinated inflammasomes for destruction. Nat Immunol (2012) 13:255-63. doi:10.1038/ni.2215

24. Zhou R, Yazdi AS, Menu P, Tschopp J. A role for mitochondria in NLRP3 inflammasome activation. Nature (2011) 469:221-5. doi:10.1038/ nature09663

25. Remijsen Q, Vanden Berghe T, Wirawan E, Asselbergh B, Parthoens E, De Rycke R, et al. Neutrophil extracellular trap cell death requires both autophagy and superoxide generation. Cell Res (2011) 21:290-304. doi:10.1038/ cr.2010.150

26. Tang S, Zhang Y, Yin SW, Gao XJ, Shi WW, Wang Y, et al. Neutrophil extracellular trap formation is associated with autophagy-related signalling in ANCA-associated vasculitis. Clin Exp Immunol (2015) 180:408-18. doi:10.1111/cei.12589

27. Itakura A, McCarty OJ. Pivotal role for the mTOR pathway in the formation of neutrophil extracellular traps via regulation of autophagy. Am J Physiol Cell Physiol (2013) 305:C348-54. doi:10.1152/ajpcell.00108.2013

28. Buffen K, Oosting M, Quintin J, Ng A, Kleinnijenhuis J, Kumar V, et al Autophagy controls BCG-induced trained immunity and the response to intravesical BCG therapy for bladder cancer. PLoS Pathog (2014) 10:e1004485. doi:10.1371/journal.ppat.1004485

29. Paul S, Kashyap AK, Jia W, He YW, Schaefer BC. Selective autophagy of the adaptor protein Bcl10 modulates T cell receptor activation of NF-kappaB. Immunity (2012) 36:947-58. doi:10.1016/j.immuni.2012.04.008

30. Chen M, Kodali S, Jang A, Kuai L, Wang J. Requirement for autophagy in the long-term persistence but not initial formation of memory B cells. J Immunol (2015) 194:2607-15. doi:10.4049/jimmunol.1403001

31. Chen M, Hong MJ, Sun H, Wang L, Shi X, Gilbert BE, et al. Essential role for autophagy in the maintenance of immunological memory against influenza infection. Nat Med (2014) 20:503-10. doi:10.1038/nm.3521

32. Sanjuan MA, Dillon CP, Tait SW, Moshiach S, Dorsey F, Connell S, et al. Toll-like receptor signalling in macrophages links the autophagy pathway to phagocytosis. Nature (2007) 450:1253-7. doi:10.1038/nature06421

33. Martinez J, Malireddi RK, Lu Q, Cunha LD, Pelletier S, Gingras S, et al. Molecular characterization of LC3-associated phagocytosis reveals distinct roles for Rubicon, NOX2 and autophagy proteins. Nat Cell Biol (2015) 17:893-906. doi:10.1038/ncb3192

34. Vergne I, Deretic V. The role of PI3P phosphatases in the regulation of autophagy. FEBS Lett (2010) 584:1313-8. doi:10.1016/j.febslet.2010.02.054

35. Brooks CR, Yeung MY, Brooks YS, Chen H, Ichimura T, Henderson JM, et al. KIM-1-/TIM-1-mediated phagocytosis links ATG5-/ULK1-dependent clearance of apoptotic cells to antigen presentation. EMBO J (2015) 34:2441-64. doi:10.15252/embj.201489838

36. Kuballa P, Nolte WM, Castoreno AB, Xavier RJ. Autophagy and the immune system. Annu Rev Immunol (2012) 30:611-46. doi:10.1146/ annurev-immunol-020711-074948

37. Deretic V, Saitoh T, Akira S. Autophagy in infection, inflammation and immunity. Nat Rev Immunol (2013) 13:722-37. doi:10.1038/nri3532

38. Martinez J, Almendinger J, Oberst A, Ness R, Dillon CP, Fitzgerald P, et al. Microtubule-associated protein 1 light chain 3 alpha (LC3)-associated phagocytosis is required for the efficient clearance of dead cells. Proc Natl Acad Sci U S A (2011) 108:17396-401. doi:10.1073/pnas.1113421108

39. Jung CH, Jun CB, Ro SH, Kim YM, Otto NM, Cao J, et al. ULK-Atg13-FIP200 complexes mediate mTOR signaling to the autophagy machinery. Mol Biol Cell (2009) 20:1992-2003. doi:10.1091/mbc.E08-12-1249

40. Florey O, Kim SE, Sandoval CP, Haynes CM, Overholtzer M. Autophagy machinery mediates macroendocytic processing and entotic cell death by targeting single membranes. Nat Cell Biol (2011) 13:1335-43. doi:10.1038/ ncb2363

41. Lenz HD, Haller E, Melzer E, Kober K, Wurster K, Stahl M, et al. Autophagy differentially controls plant basal immunity to biotrophic and necrotrophic pathogens. Plant J (2011) 66:818-30. doi:10.1111/j.1365-313X.2011.04546.x 
42. Harris J. Autophagy and cytokines. Cytokine (2011) 56:140-4. doi:10.1016/j. cyto.2011.08.022

43. Kanayama M, Inoue M, Danzaki K, Hammer G, He YW, Shinohara ML. Autophagy enhances NFkappaB activity in specific tissue macrophages by sequestering A20 to boost antifungal immunity. Nat Commun (2015) 6:5779. doi:10.1038/ncomms6779

44. Smeekens SP, Malireddi RK, Plantinga TS, Buffen K, Oosting M, Joosten LA, et al. Autophagy is redundant for the host defense against systemic Candida albicans infections. Eur J Clin Microbiol Infect Dis (2014) 33:711-22. doi:10.1007/s10096-013-2002-x

45. Tam JM, Mansour MK, Khan NS, Seward M, Puranam S, Tanne A, et al. Dectin-1-dependent LC3 recruitment to phagosomes enhances fungicidal activity in macrophages. J Infect Dis (2014) 210(11):1844-54. doi:10.1093/ infdis/jiu290

46. Brothers KM, Gratacap RL, Barker SE, Newman ZR, Norum A, Wheeler RT. NADPH oxidase-driven phagocyte recruitment controls Candida albicans filamentous growth and prevents mortality. PLoS Pathog (2013) 9:e1003634. doi:10.1371/journal.ppat.1003634

47. Ma J, Becker C, Lowell CA, Underhill DM. Dectin-1-triggered recruitment of light chain 3 protein to phagosomes facilitates major histocompatibility complex class II presentation of fungal-derived antigens. J Biol Chem (2012) 287:34149-56. doi:10.1074/jbc.M112.382812

48. Gow NA, Netea MG, Munro CA, Ferwerda G, Bates S, Mora-Montes HM, et al. Immune recognition of Candida albicans beta-glucan by dectin-1.J Infect Dis (2007) 196:1565-71. doi:10.1086/523110

49. Gantner BN, Simmons RM, Underhill DM. Dectin-1 mediates macrophage recognition of Candida albicans yeast but not filaments. EMBO J (2005) 24:1277-86. doi:10.1038/sj.emboj.7600594

50. Nicola AM, Albuquerque P, Martinez LR, Dal-Rosso RA, Saylor C, De Jesus $\mathrm{M}$, et al. Macrophage autophagy in immunity to Cryptococcus neoformans and Candida albicans. Infect Immun (2012) 80:3065-76. doi:10.1128/IAI.00358-12

51. Saijo S, Fujikado N, Furuta T, Chung SH, Kotaki H, Seki K, et al. Dectin-1 is required for host defense against Pneumocystis carinii but not against Candida albicans. Nat Immunol (2007) 8:39-46. doi:10.1038/ni1425

52. Taylor PR, Tsoni SV, Willment JA, Dennehy KM, Rosas M, Findon H, et al. Dectin-1 is required for beta-glucan recognition and control of fungal infection. Nat Immunol (2007) 8:31-8. doi:10.1038/ni1408

53. Rosentul DC, Plantinga TS, Farcas M, Oosting M, Hamza OJ, Scott WK, et al. Role of autophagy genetic variants for the risk of Candida infections. Med Mycol (2014) 52:333-41. doi:10.1093/mmy/myt035

54. Qin QM, Luo J, Lin X, Pei J, Li L, Ficht TA, et al. Functional analysis of host factors that mediate the intracellular lifestyle of Cryptococcus neoformans. PLoS Pathog (2011) 7:e1002078. doi:10.1371/journal.ppat.1002078

55. Kyrmizi I, Gresnigt MS, Akoumianaki T, Samonis G, Sidiropoulos P, Boumpas D, et al. Corticosteroids block autophagy protein recruitment in Aspergillus fumigatus phagosomes via targeting dectin-1/Syk kinase signaling. J Immunol (2013) 191:1287-99. doi:10.4049/jimmunol.1300132

56. Falcone EL, Holland SM. Invasive fungal infection in chronic granulomatous disease: insights into pathogenesis and management. Curr Opin Infect Dis (2012) 25:658-69. doi:10.1097/QCO.0b013e328358b0a4

57. Palmer LB, Greenberg HE, Schiff MJ. Corticosteroid treatment as a risk factor for invasive aspergillosis in patients with lung disease. Thorax (1991) 46:15-20. doi:10.1136/thx.46.1.15

58. de Luca A, Smeekens SP, Casagrande A, Iannitti R, Conway KL, Gresnigt MS, et al. IL-1 receptor blockade restores autophagy and reduces inflammation in chronic granulomatous disease in mice and in humans. Proc Natl Acad Sci U $S$ A (2014) 111:3526-31. doi:10.1073/pnas.1322831111

59. Gross O, Poeck H, Bscheider M, Dostert C, Hannesschlager N, Endres S, et al. Syk kinase signalling couples to the Nlrp3 inflammasome for anti-fungal host defence. Nature (2009) 459:433-6. doi:10.1038/nature07965

60. Karki R, Man SM, Malireddi RK, Gurung P, Vogel P, Lamkanfi M, et al. Concerted activation of the AIM2 and NLRP3 inflammasomes orchestrates host protection against Aspergillus infection. Cell Host Microbe (2015) 17:357-68. doi:10.1016/j.chom.2015.01.006
61. van de Veerdonk FL, Joosten LA, Shaw PJ, Smeekens SP, Malireddi RK, van der Meer JW, et al. The inflammasome drives protective Th1 and Th17 cellular responses in disseminated candidiasis. Eur J Immunol (2011) 41:2260-8. doi:10.1002/eji.201041226

62. Rieber N, Hector A, Kuijpers T, Roos D, Hartl D. Current concepts of hyperinflammation in chronic granulomatous disease. Clin Dev Immunol (2012) 2012:252460. doi:10.1155/2012/252460

63. Meissner F, Seger RA, Moshous D, Fischer A, Reichenbach J, Zychlinsky A. Inflammasome activation in NADPH oxidase defective mononuclear phagocytes from patients with chronic granulomatous disease. Blood (2010) 116:1570-3. doi:10.1182/blood-2010-01-264218

64. van de Veerdonk FL, Smeekens SP, Joosten LA, Kullberg BJ, Dinarello CA, van der Meer JW, et al. Reactive oxygen species-independent activation of the IL-1beta inflammasome in cells from patients with chronic granulomatous disease. Proc Natl Acad Sci U S A (2010) 107:3030-3. doi:10.1073/ pnas. 0914795107

65. Kanayama M, He YW, Shinohara ML. The lung is protected from spontaneous inflammation by autophagy in myeloid cells. J Immunol (2015) 194:5465-71. doi:10.4049/jimmunol.1403249

66. Hammer GE, Turer EE, Taylor KE, Fang CJ, Advincula R, Oshima S, et al. Expression of A20 by dendritic cells preserves immune homeostasis and prevents colitis and spondyloarthritis. Nat Immunol (2011) 12:1184-93. doi:10.1038/ni.2135

67. Boone DL, Turer EE, Lee EG, Ahmad RC, Wheeler MT, Tsui C, et al. The ubiquitin-modifying enzyme A20 is required for termination of Toll-like receptor responses. Nat Immunol (2004) 5:1052-60. doi:10.1038/ni1110

68. Lee EG, Boone DL, Chai S, Libby SL, Chien M, Lodolce JP, et al. Failure to regulate TNF-induced NF-kappaB and cell death responses in A20-deficient mice. Science (2000) 289:2350-4. doi:10.1126/science.289.5488.2350

69. Shi CS, Kehrl JH. TRAF6 and A20 regulate lysine 63-linked ubiquitination of Beclin-1 to control TLR4-induced autophagy. Sci Signal (2010) 3:ra42. doi:10.1126/scisignal.2000751

70. Matsuzawa Y, Oshima S, Takahara M, Maeyashiki C, Nemoto Y, Kobayashi $\mathrm{M}$, et al. TNFAIP3 promotes survival of CD4 T cells by restricting MTOR and promoting autophagy. Autophagy (2015) 11:1052-62. doi:10.1080/1554 8627.2015.1055439

71. Schlie K, Westerback A, DeVorkin L, Hughson LR, Brandon JM, MacPherson $\mathrm{S}$, et al. Survival of effector CD8+ T cells during influenza infection is dependent on autophagy. J Immunol (2015) 194:4277-86. doi:10.4049/ jimmunol.1402571

72. Pua HH, Dzhagalov I, Chuck M, Mizushima N, He YW. A critical role for the autophagy gene Atg5 in T cell survival and proliferation. J Exp Med (2007) 204:25-31. doi:10.1084/jem.20061303

73. Weindel CG, Richey LJ, Bolland S, Mehta AJ, Kearney JF, Huber BT. B cell autophagy mediates TLR7-dependent autoimmunity and inflammation. Autophagy (2015) 11:1010-24. doi:10.1080/15548627.2015.1052206

74. Eriksen AB, Torgersen ML, Holm KL, Abrahamsen G, Spurkland A, Moskaug JO, et al. Retinoic acid-induced IgG production in TLR-activated human primary B cells involves ULK1-mediated autophagy. Autophagy (2015) 11:460-71. doi:10.1080/15548627.2015.1009797

75. Lee HK, Mattei LM, Steinberg BE, Alberts P, Lee YH, Chervonsky A, et al. In vivo requirement for Atg 5 in antigen presentation by dendritic cells. Immunity (2010) 32:227-39. doi:10.1016/j.immuni.2009.12.006

Conflict of Interest Statement: The authors declare that the research was conducted in the absence of any commercial or financial relationships that could be construed as a potential conflict of interest.

Copyright $\odot 2016$ Kanayama and Shinohara. This is an open-access article distributed under the terms of the Creative Commons Attribution License (CC BY). The use, distribution or reproduction in other forums is permitted, provided the original author(s) or licensor are credited and that the original publication in this journal is cited, in accordance with accepted academic practice. No use, distribution or reproduction is permitted which does not comply with these terms. 